\title{
Isotopic Analyses of Barium in Meteorites and in Terrestrial Samples ${ }^{1}$
}

\author{
O. Eugster, F. Tera, and G. J. Wasserburg \\ Charles Arms Laboratory of the Division of Geological Sciences \\ California Institute of Technology, Pasadena, California 91109
}

\begin{abstract}
Isotopic composstion and concentration of barium in six stone meteorites and the silicate inclusions of two iron inetforites and three terrestrial samples were measured by use of a 'double spike' isotopic dilutıon terhnique in order to correct for laboratory fractionation. Any differences between the abundances of the isotopes in meteoritic and terrestrial $\mathrm{Ba}$ were found to be less than $\mathbf{0 . 1 \%}$ for all isotopes. The per cent abundances of $\mathrm{Ba}$ found in our work for $\mathrm{Ba}^{138}, \mathrm{Ba}^{137}, \mathrm{Ba}^{184}, \mathrm{Ba}^{135}, \mathrm{Ba}^{124}, \mathrm{Ba}^{152}$, and $\mathrm{Ba}^{130}$ are $71.699,11.232,7.853,6.592,2.417,0.1012$, and 0.1058 , respectively. Because of the higher precision, these abundances should replace the currently accepted values. These results show the variations in the $\mathrm{Ba}$ isotopes reported by S. Umemoto (1962) to be unsubstantiated.
\end{abstract}

\section{INTRODUCTION}

A comparison of the isotopic composition of various elements in terrestrial samples, meteorites, and other materials of the solar system is of fundamental importance in determining the early history of the solar system and the mechanisms of nucleosynthesis. In addition to effects that are a product of either long-lived natural activity or cosmic-ray interaction with meteoritic material, isotopic abundances may be distinct from terrestrial material because of isotopic fractionation or incomplete isotopic homogenization during the formation of the solar system. The only major variation in isotopic abundances observed between terrestrial and meteoritic samples that is not caused by nuclear processes is found in the rare gases neon [Pepin, 1967], krypton [Eugster et al., 1967], and xenon [Reynolds, 1960a]. The only apparent exceptions to the constancy of the isotopic abundances, with the exception of the rare gases, are the elements lithium and barium. Investigations of lithium by Gradsztajn et al. [1967] suggest that there is a variation of the abundance of lithium in stone meteorites of about $10 \%$. These data have not yet been confirmed by work in other laboratories.

1 Contribution 1606 of the California Institute of Technology.

Copyright () 1969 by the American Geophysical Union.
Umemoto [1962] reported that the isotopio composition of $\mathrm{Ba}$ in the Bruderheim chondrite and in the Pasamonte and Nuevo Laredo achondrites were distinct from terrestrial $\mathrm{Ba}$ and showed a pattern of uniform fractionation relative to terrestrial $\mathrm{Ba}$. The enrichments observed by him correspond to a $2 \%$ enrichment in the ratio $\mathrm{Ba}^{130} / \mathrm{Ba}^{139}$ compared with terrestrial materials. Previously, Krummenacher et al. [1962] found no anomalies greater than $3 \%$ for the isotopes $\mathrm{Ba}^{134-138}$ in the Richardton chondrite. Since the established fractionation patterns for $\mathrm{Xe}$ and the suggested fractionation of $\mathrm{Ba}$ reported by Umemoto were in the same direction, it was of great interest to confirm or disprove the reality of this reported effect. The mechanisms for fractionation that have been proposed for $\mathrm{Xe}$ and $\mathrm{Kr}$ are far from satisfactory, and it was conceivable that some unknown mechanism might have also operated in fractionating the $\mathrm{Ba}$ isotopes. The magnitude of the fractionation proposed by Umemoto was significantly smaller than that found for $\mathrm{Xe}$, which is approximately $4 \%$ per mass unit, whereas for $\mathrm{Ba}$ Umemoto indicated an effect of $0.25 \%$ per mass unit. It is well known that isotopic fractionation may be induced during mass spectrometric analysis, and great care must be taken to avoid the production of this type of anomaly by laboratory procedures. This is made quite evident by the work of Wetherill [1964] on molybdenum, who demonstrated that the variations in molyb- 
TABLE 1. Isotopic Composition of the Double Spike Atom per cent abundances.

\begin{tabular}{|c|c|c|c|c|c|c|c|}
\hline & $\mathrm{Ba}^{138}$ & $\mathbf{B a}^{137}$ & $\mathrm{Ba}^{136}$ & $\mathbf{B a}^{125}$ & $\mathrm{Ba}^{134}$ & $\mathrm{Ba}^{132}$ & $\mathrm{Ba}^{130}$ \\
\hline 1. Enriched $\mathrm{Ba}^{137}$, measured & 9.697 & 89.457 & 0.660 & 0.1290 & 0.0543 & 0.00119 & 0.00070 \\
\hline & \pm .060 & \pm .070 & \pm .006 & \pm .0030 & \pm .0010 & \pm .00005 & \pm .00005 \\
\hline Enriched $\mathrm{Ba}^{134}$, measured & 7.867 & 1.646 & 1.789 & 4.080 & 84.572 & 0.0351 & 0.0115 \\
\hline & \pm .150 & \pm .025 & \pm .018 & \pm .020 & \pm .200 & \pm .0004 & $\begin{array}{l} \pm .0003 \\
0.00253\end{array}$ \\
\hline $\begin{array}{l}\text { 3. Calculated composition of } \\
\text { double spike based on com- } \\
\text { positions of } 1 \text { and } 2 \text { and on } \\
\text { the amounts of } \mathrm{Ba} \text { taken from } \\
\text { the two salts* }\end{array}$ & $\begin{array}{r}9.387 \\
\pm .064\end{array}$ & $\begin{array}{l}74.555 \\
\pm .058\end{array}$ & $\begin{array}{r}0.8515 \\
\pm .0059\end{array}$ & $\begin{array}{r}0.7995 \\
\pm .0040\end{array}$ & $\begin{array}{l}14.398 \\
\pm .034\end{array}$ & $\begin{array}{r}0.00695 \\
\pm .00008\end{array}$ & $\begin{array}{r}0.00253 \\
\pm .00007\end{array}$ \\
\hline $\begin{array}{l}\text { 4. Measured composition of } \\
\text { double spike, normalized to } \\
\mathrm{Ba}^{187} / \mathrm{Ba}^{134}=5.178\end{array}$ & $\begin{array}{r}9.338 \\
\pm .004\end{array}$ & 74.598 & $\begin{array}{r}0.8500 \\
\pm .0014\end{array}$ & $\begin{array}{r}0.7967 \\
\pm .0014\end{array}$ & 14.407 & $\begin{array}{r}0.00690 \\
\pm .00007\end{array}$ & $\begin{array}{r}0.00251 \\
\pm .00006\end{array}$ \\
\hline $\begin{array}{l}\text { 5. Typical composition of a } \\
\text { mixture of double spike plus } \\
\text { sample, not corrected for } \\
\text { fractionation (Nuevo Laredo) }\end{array}$ & $\begin{array}{r}39.403 \\
\pm .010\end{array}$ & $\begin{array}{l}44.020 \\
\pm .010\end{array}$ & $\begin{array}{r}4.2322 \\
\pm .0010\end{array}$ & $\begin{array}{r}3.5990 \\
\pm .0010\end{array}$ & $\begin{array}{r}8.641 \\
\pm .010\end{array}$ & $\begin{array}{r}0.05260 \\
\pm .00005\end{array}$ & $\begin{array}{r}0.05270 \\
\pm .00005\end{array}$ \\
\hline
\end{tabular}

Notes.

For 1 and 2 the total errors are based on the errors for the uncertainty of the fractionation and on the statistical errors. The total error equals $\left[\sum_{i}\left(\sigma_{i}\right)^{2}\right]^{1 / 2}$. For 3 the errors are based on the errors of 1 and 2. For 4 and 5 statistical errors are shown.

* For the double spike the ratio of the total number of $\mathrm{Ba}$ atoms contributed by the enriched $\mathrm{Ba}^{137}$ salt to the total number of $\mathrm{Ba}$ atoms contributed by the enriched $\mathrm{Ba}^{134}$ salt was 4.8929 as calculated from the gravimetric data and from the atomic weights of the enriched $\mathrm{Ba}$ which was based on 1 and 2 , respectively.

denum isotopic abundances reported by Murthy [1962, 1963, 1964] were most likely due to instrumental fractionation. In this light, the isotopic variations of Mo in terrestrial ore samples reported by Crouch and Tuplin [1964] appear very doubtful. These authors seem to be unaware of the other work in this field and the instrumental problems that invariably exist. Chakraburtty et al. [1964] reported that no enrichment of $\mathrm{Ag}^{107}$ was found in seven iron meteorites, including Canyon Diablo for which an anomaly was reported by Murthy [1960], which was most likely the effect of instrumental fractionation.

It is known [Shields, 1966] that isotopic fractionation effects can be minimized by very standard operational procedures during analysis. It was deemed advisable, however, to utilize a more reliable technique such as an internal isotopic standard of two isotopes. This technique, often called the double spiking technique, was recently used by Wetherill [1964] in his study on molybdenum. To distinguish between laboratory effects caused either by chemistry or mass spectrometry, an isotopic internal standard or double spike was added to the samples before the chemical separation.

\section{Experimental Procedure}

Chemical treatment. A 0.2- to 5-gram sample was mechanically cleaned with a dental burr to remove any surface contamination, washed with acetone, dried in an oven, and, after grinding and splitting, weighed into a $100-\mathrm{ml}$ teflon beaker. The sample was dissolved in $\mathrm{HClO}$, and $\mathrm{HF}, 5 \mathrm{ml}$ of each acid per gram solid sample, evaporated to dryness, and redissolved in $2.5 \mathrm{~N} \mathrm{HCl}$. An aliquot corresponding to about 0.2 gram of solid sample was taken, evaporated to dryness, and then brought into solution in $2 \mathrm{ml}$ of $2 \mathrm{~N} \mathrm{HCl}$ which was loaded onto a cation exchange column $(1 \mathrm{~cm} \times 15 \mathrm{~cm}$, packed with Dowex $50 \times 8,200-400$ mesh). After most of the other elements were removed with 4 column volumes of $4 \mathrm{~N} \mathrm{HCl}$, the barium was collected in the following fraction of about 2 column volumes of $4 \mathrm{~N} \mathrm{HCl}$.

Blank determinations showed that the barium contamination introduced by the complete chemical processing was less than $5 \times 10^{-0}$ gram. This blank contribution to the sample was always less than $2 \%$, which is negligible insofar as the isotopic ratios are concerned. The $\mathrm{Ba}$ concentrations were, however, corrected for this small blank. 
Mass spectrometry. The sample of approximately $10^{-6}$ gram barium was deposited as the chloride and analyzed by means of the singlefilament ( $\mathrm{Ta}$ ) surface ionization technique. A single-focusing, $30.48-\mathrm{cm}$ radius, $60^{\circ}$ sector type, programmable magnetic field mass spectrometer with digital output and with on-line data processing [Wasserburg et al., 1968, 1969] was used for most analyses. Some of the unspiked samples were analyzed with the same mass spectrometer by using a recorder for analog output.

The mass spectrometric data were taken in sets of ten complete sweeps of the spectrum. Because of the programmable magnetic field device and the on-line data processing, one set of data for all isotopes including zeros on each side of every peak could be taken within about 10 minutes. Systematic changes in the isotopic ratios during this time were less than 2 parts in $10^{4}$ for all ratios. We therefore assume the fractionation during each set to be constant. One analysis of a double spiked sample consisted of six to ten sets taken at different intensities ranging in most cases from about 0.5 to 12 volts for $\mathrm{Ba}^{138}$ with a $10^{11}$-ohm input resistor. The linearity of this resistor was examined carefully up to 42 volts. Four different samples were used for this examination. Their isotopic com- position was as shown in Table 1 for a typical composition of a mixture of double spike plus sample. The $\mathrm{Ba}^{185} / \mathrm{Ba}^{195}$ ratios were always be: tween 11 and 14. These ratios have been corrected for the mass spectrometer fractionation, which was based on the ratio $\mathrm{Ba}^{130} / \mathrm{Ba}^{185}$. For all four samples this ratio was between 1.17 and 1.18. Figure 1 shows the variation of the ratio $\mathrm{Ba}^{137} / \mathrm{Ba}^{135}$ as a function of the $\mathrm{Ba}^{137}$ ion current normalized to the value of this ratio obtained at about 0.4 volt. Below 12 volts the input resistor can be considered to be linear within $0.1 \%$. In a few cases in which data were taken at intensities over 12 volts, corrections were applied for the nonlinearity.

Because of the wide range (up to $10^{3}$ ) in ion currents of the different isotopes, it was necessary to eliminate errors caused by the incomplete discharge of the high input resistor and the amplifier system. Time intervals between data acquisition were established by making a time study of normal potassium, so that any errors due to these sources were less than 1 part in $10^{4}$ for all isotopes. This effect was also minimized by a scanning sequence in which a high-abundance isotope did not immediately precede a rare isotope in the detector. In the chosen scanning sequence $\mathrm{Ba}^{132}$ usually

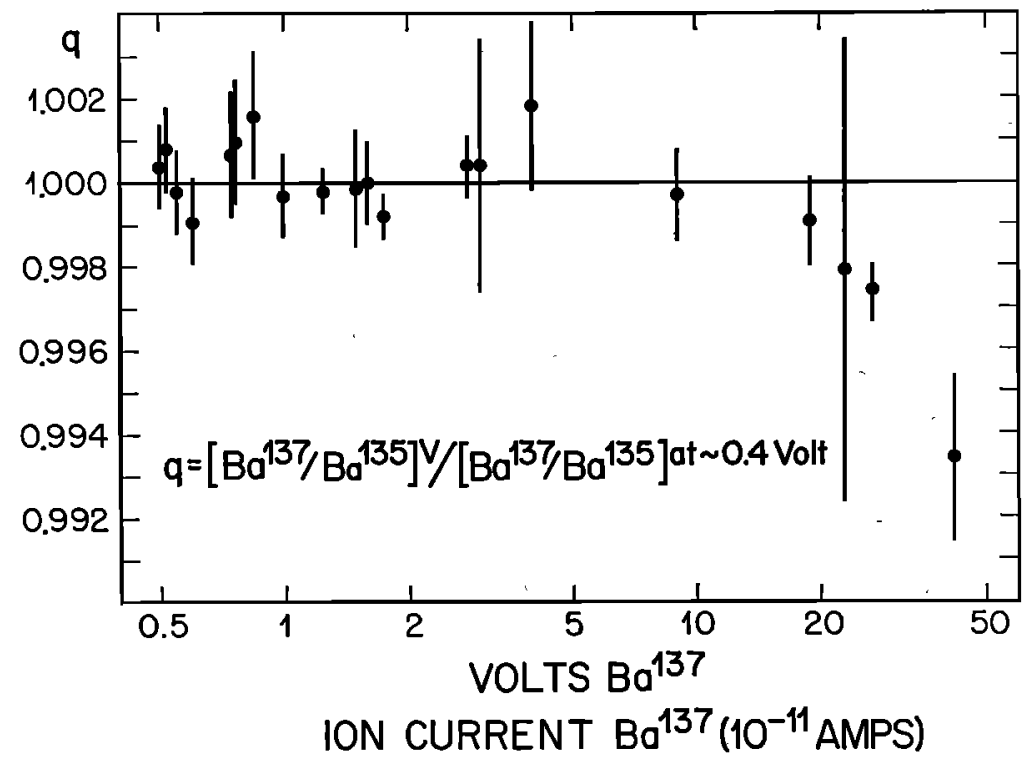

Fig. 1. Voltage dependence $q$ of the $10^{12}-\mathrm{hm}$ resistor used as a function of ion current. The $\mathrm{Ba}^{137} / \mathrm{Ba}^{135}$ ratios are corrected for changes in fractionation. Each point represents the mean of a set of ten ratios. Errors shown are the mean deviations. 
followed $\mathrm{Ba}^{\mathrm{as}}$. This sequence represented the greatest difference between a high- and lowintensity isotope. The ratio $\mathrm{Ba}^{125} / \mathrm{Ba}^{120}$ was always about 68 . The isotope $\mathrm{Ba}^{100}$ was measured twice successively, integrating both times at least 12 seconds (including the zero lines). So we were able to detect any possible errors due to incomplete discharge of the input system.

\section{Double SPIKI}

Highly enriched and precisely weighed $\mathrm{Ba}^{184}\left(\mathrm{NO}_{3}\right)_{2}$ and $\mathrm{Ba}^{287}\left(\mathrm{NO}_{3}\right)_{2}$ obtained from Oak Ridge were used to prepare standard solutions of $\mathrm{Ba}^{134}$ and $\mathrm{Ba}^{137}$ in $2.5 \mathrm{~N} \mathrm{HCl}$. The isotopic composition of these two solutions were determined and are given in Table 1 . The data as tabulated are uncorrected for mass spectrometer fractionation. The relative abundance of $\mathrm{Ba}^{\text {Bat }}$ in the enriched $\mathrm{Ba}^{137}$ and that of $\mathrm{Ba}^{137}$ in the enriched $\mathrm{Ba}^{184}$ were each less than $2 \%$. The atom fraction of the principal isotope $\left(\mathrm{Ba}^{134}\right.$ and $\mathrm{Ba}^{157}$, respectively) in the two solutions is considered to be accurate to within 0.3 and $0.1 \%$, respectively. The absolute stochiometric composition of the salts used was not demonstrated; however, cation impurities were estimated to be below $0.1 \%$ based on ORNL spectroscopic analyses.

By assuming the salts to be stochiometric and using the measured isotopic abundances, a double spike was prepared by mixing aliquots of the two solutions to give a calculated ratio $\mathrm{Ba}^{197} / \mathrm{Ba}^{184}=5.178$. The measured isotopic composition of the double spike corrected for discrimination using $\mathrm{Ba}^{157} / \mathrm{Ba}^{134}=5.178$ is given in Table 1 and is compatible with the results given for the compositions of the separate spikes within the errors given.

A normal $\mathrm{Ba}$ standard ( $\mathrm{BaCO}_{3}$ spec. pure, Johnson, Mathey, and Co.) with a gravimetrically determined concentration of $2.816 \times 10^{-9}$ mol $\mathrm{Ba}^{138} / \mathrm{g}$ solution was mixed with the double spike and analyzed. The fractionation was determined for this analysis by the double spike technique as described below. The isotopic composition of the double spike was as given in Table 1 (measured composition) and the concentration of $\mathrm{Ba}^{\mathrm{an}}$ in the double spike was $0.6257 \times 10^{-0} \mathrm{~mol} / \mathrm{g}$ solution as determined from gravimetry and from the measured isotopic composition of $\mathrm{Ba}$ in the separate nitrates (Table 1). The isotopic composition of normal $\mathrm{Ba}$ was as reported in this work. The concentration of $\mathrm{Ba}^{139}$ in the normal $\mathrm{Ba}$ standard calculated by two independent isotopic dilution experiments were 2.819 and $2.822 \times 10^{-8} \mathrm{~mol} / \mathrm{g}$ solution, respectively. The differences between these values and the gravimetrically determined concentration of the normal $\mathrm{Ba}$ standard are well within the errors for the gravimetry and the stochiometry of the salts, the gravimetry of the aliquots taken and the analytical errors.

The double spike was added to the sample before the chemical separation in such a way that over $85 \%$ of $\mathrm{Ba}^{134}$ and $\mathrm{Ba}^{137}$, respectively, originated from the double spike, whereas over $85 \%$ of the other isotopes originated from the sample. A typical composition of a mixture of the double spike plus sample is included in Table 1. Any subsequent fractionation, either in the chemical separation or in the mass spectrometric analyses is therefore corrected for in this procedure. The proportions of double spike and sample were kept constant in most cases to within $10 \%$ to minimize error propagation. In addition, the same mass spectrometric measurements permitted a determination of the $\mathrm{Ba}$ concentration in the sample since the use of a double spike is essentially an isotope dilution with two spike isotopes.

The mixture of sample barium and double spike was analyzed on the mass spectrometer, and the difference in the fractionation factor per mass unit was determined from the equation

$$
\begin{aligned}
& \left(\frac{137}{134}\right)_{\mathrm{spiko}}^{M}=\left(\frac{137}{134}\right)_{\mathrm{mix}}^{M}\left[1-3\left(\alpha^{\prime \prime}-\alpha^{\prime}\right)\right]+\left\{\left(\frac{138}{134}\right)_{\mathrm{mix}}^{M}\left[1-4\left(\alpha^{\prime \prime}-\alpha^{\prime}\right)\right]-\left(\frac{138}{134}\right)_{\mathrm{spiko}}^{M}\right\} \\
& \times \frac{\left\{\left(\frac{137}{134}\right)_{\text {mix }}^{M}\left[1-3\left(\alpha^{\prime \prime}-\alpha^{\prime}\right)\right]\left(\frac{134}{138}\right)_{\text {amplo }}^{\text {true }}\left[1-4 \alpha^{\prime}\right]-\left(\frac{137}{138}\right)_{\text {amplo }}^{\text {true }}\left[1-\alpha^{\prime}\right]\right\}}{1-\left(\frac{138}{134}\right)_{\text {mix }}^{M}\left[1-4\left(\alpha^{\prime \prime}-\alpha^{\prime}\right)\right]\left(\frac{134}{138}\right)_{\text {amplo }}^{\text {true }}\left[1-4 \alpha^{\prime}\right]}
\end{aligned}
$$


where $\alpha^{\prime}$ is defined by

$$
\left(\frac{137}{134}\right)_{\text {npike }}^{x} /\left(\frac{137}{134}\right)_{\text {spike }}^{\text {true }}=1+3 \alpha^{\prime}
$$

and $\alpha^{\prime \prime}$ by example of the calculation for the case of the ratio $\mathrm{Ba}^{130} / \mathrm{Ba}^{139}$. The ratios for the mixture of the double spike plus sample (subscript mix) originate from the same particular analysis as for equation 1.

$$
\begin{aligned}
\left(\frac{130}{138}\right)_{\text {ampla }}^{\alpha^{\prime}}=\left(\frac{130}{138}\right)_{\text {mix }}^{M}[1+ & \left.8\left(\alpha^{\prime \prime}-\alpha^{\prime}\right)\right] \\
+ & \frac{\left\{\left(\frac{130}{138}\right)_{\text {mix }}^{M}\left[1+8\left(\alpha^{\prime \prime}-\alpha^{\prime}\right)\right]\left(\frac{138}{134}\right)_{\text {apike }}^{M}-\left(\frac{130}{134}\right)_{\text {aplke }}^{M}\right\}}{\left(\frac{138}{134}\right)_{\text {mix }}^{M}\left[1-4\left(\alpha^{\prime \prime}-\alpha^{\prime}\right)\right]-\left(\frac{138}{134}\right)_{\text {opike }}^{M}} \\
& \cdot\left\{1-\left(\frac{138}{134}\right)_{\text {mix }}^{M}\left[1-4\left(\alpha^{\prime \prime}-\alpha^{\prime}\right)\right]\left(\frac{134}{138}\right)_{\text {samplo }}^{\text {true }}\left[1-4 \alpha^{\prime}\right]\right\}
\end{aligned}
$$

$$
\left(\frac{137}{134}\right)_{\text {mix }}^{M} /\left(\frac{137}{134}\right)_{\text {mix }}^{\text {true }}=1+3 \alpha^{\prime \prime}
$$

Here $\alpha^{\prime}$ and $\alpha^{\prime \prime}$ are the fractionation factors per mass unit for the spike analysis and for the mixture of double spike plus sample, respectively. The superscript $M$ always represents measured values on the mass spectrometer and the superscripts true represent the absolute ratios. The ratios indicated by the subscript spike are the ratios in the pure double spike; those indicated by the subscript sample are the ratios in the sample; those indicated by the subscript mix are the ratios in the mixture of double spike plus sample.

The spiking was done so that the second term in equation 1 was always less than $2 \%$ of the first term; i.e.

$$
\left(\frac{137}{134}\right)_{\text {apike }}^{M} \sim 1.02\left(\frac{137}{134}\right)_{\text {mix }}^{M U}
$$

The difference $\alpha^{\prime \prime}-\alpha^{\prime}$ was calculated directly or by an iterative procedure by using the experimental results for each run and the independently measured spike composition run (Table 1). The error in $\alpha^{\prime \prime}-\alpha^{\prime}$ contributed by an uncertainty in the absolute abundances of $1 \%$ per mass unit would be less than $1 \%$ of $\alpha^{\prime \prime}-\alpha^{\prime}$. The values of $\alpha^{\prime \prime}-\alpha^{\prime}$ were always less than 2 parts in $10^{3}$.

The knowledge of the difference $\alpha^{\prime \prime}-\alpha$ allows the calculation of isotopic ratios in the sample as if they had the same fractionation $\alpha^{\prime}$ as that for the analysis of the pure double spike as given in Table 1. Equation 2 is an where $(130 / 138)_{\text {samplo }}^{\alpha^{*}}$ is defined by

$$
\left(\frac{130}{138}\right)_{\text {sample }}^{\alpha^{\prime}} /\left(\frac{130}{138}\right)_{\text {samplo }}^{\text {true }}=1-8 \alpha^{\prime}
$$

The second term in equation 2 was for all sample ratios of Table 4 approximately $10 \%$ of the first term

$$
\left[\left(\frac{130}{138}\right)_{\text {ample }}^{\alpha^{\prime}} \sim 1.1\left(\frac{130}{138}\right)_{\operatorname{mix}}^{M}\right]
$$

The ratio $(130 / 138)_{\text {amplo }}^{\alpha^{\circ}}$ is the isotopic ratio of $\mathrm{Ba}^{130} / \mathrm{Ba}^{138}$ in the sample as if it had undergone the same fractionation per mass unit $\alpha^{\prime}$ as the pure double spike. The other isotopic ratios in the sample as tabulated (Table 4) are all calculated similarly.

Returning to a consideration of the error propagation for this procedure from the calibration of the normal $\mathrm{Ba}$ salt with the double spike, it follows that the possible gravimetric errors in the double spike solution are only constrained by $(\epsilon / 3)-(4 \eta / 3)<$ fractional error in the $\mathrm{Ba}^{18 s}$ calibration $\sim 2 \times 10^{-3}$.

Here

$$
\epsilon=\frac{\left[C^{134}\right]^{\text {true }}-\left[C^{134}\right]^{\text {ass }}}{\left[C^{134}\right]^{\text {sad }}}
$$

and

$$
\eta=\frac{\left[C^{137}\right]^{\text {trub }}-\left[C^{137}\right]^{\text {ass }}}{\left[C^{137}\right]^{\text {sas }}}
$$

where $\left[C^{12 s}\right]$ is the concentration of $\mathrm{Ba}^{124}$ in the double spike. The superscript ass represents the assumed concentration based on the gravimetry of the salts. 
Because of the lack of knowledge of the absolute stochiometry of the salts composing the double spike, it is not possible to draw any strong conclusions about the absolute fractionation $\alpha^{\prime}$ from these data.

To demonstrate the sensitivity of the double spike technique, the ratio $(137 / 134)^{\text {wplke }}$ of the double spike was changed, adding to the original amount of $\mathrm{Ba}^{137}$ in the double spike 9 parts in $10^{4}$ of pure fission produced $\mathrm{Ba}^{137}$. This enriched double spike was mixed with an aliquot of the Forest City sample (Table 4) and analyzed. The ratio of $(137 / 134)^{{ }^{M}}{ }_{\text {"p } / k^{*}}$ in the slightly enriched double spike would thus be a factor of $(1+0.0009)$ greater than in the original double spike, all other ratios being essentially unchanged. Returning to equation 1 , which determines the mass spectrometer discrimination, we have

$$
\begin{aligned}
\left(\frac{137}{134}\right)_{\mathrm{spike*}}^{M} & =\left(1+9 \times 10^{-4}\right)\left(\frac{137}{134}\right)_{\mathrm{spike}}^{M} \\
& =\left[1-3\left(\alpha^{\prime \prime}-\alpha^{\prime}\right)\right]\left(\frac{137}{134}\right)_{\text {mix }}^{M}+R
\end{aligned}
$$

where $R$ is unchanged from the original double spike. To the necessary accuracy

$$
\begin{aligned}
\left(\frac{137}{134}\right)_{\mathrm{spike}}^{M}= & {\left[1-3\left(\alpha^{\prime \prime}+3 \times 10^{-4}-\alpha^{\prime}\right)\right] } \\
& \cdot\left(\frac{137}{134}\right)_{\mathrm{mix}}^{M}+R\left(1-9 \times 10^{-4}\right)
\end{aligned}
$$

Here $\alpha^{\prime \prime}$ and $\alpha^{\prime}$ are again the true instrumental fractionation factors. If we were to calculate the discrimination difference in the experiment with the enriched double spike as if there were no $\mathrm{Ba}^{137}$ added, we would obtain a false fractionation difference $\alpha^{*}-\alpha^{\prime}$ of approximately

$$
\alpha^{*}-\alpha^{\prime}=\alpha^{\prime \prime}+3 \times 10^{-4}-\alpha^{\prime}
$$

and would thus attribute an inherent fractionation of 3 parts in $10^{4}$ per mass unit to the sample. Inspection of these equations shows that this is equivalent to measuring a sample that was chemically fractionated by this amount. This corresponds to a sample fractionation for $\mathrm{Ba}^{180} / \mathrm{Ba}^{138}$ of

$$
\begin{gathered}
\left(\frac{130}{138}\right)_{\substack{\text { ample } \\
\text { fraotionated }}}^{a^{\prime}}=\left(1+8 \times 3 \times 10^{-4}\right) \\
\cdot\left(\frac{130}{138}\right)_{\substack{\text { sample } \\
\text { unf ractionated }}}^{\alpha^{\prime}}
\end{gathered}
$$

Table 2 shows the results for the enrichment experiment compared with the results for an aliquot of the same sample whose double spike has not been enriched. The measured differences are in good agreement with the differences calculated according to equations 3 and 4 .

This experiment shows that a true fractionation of 3 parts in $10^{4}$ per mass unit can clearly be detected by the described technique.

\section{Results and Discussion}

Isotopic ratios of barium. The results for the analyses of three unspiked meteorites are shown in Table 3. Since these analyses were carried out when the automatic digitized data acquisition system was still in an early stage of completion, some of the data had to be taken by the usual analog technique by measuring the peak heights on a strip chart.

TABLE 2. Results for Two Runs of the Forest City Chondrite Double Spiked with $\mathrm{Ba}^{134}$ and $\mathrm{Ba}^{137}$ The double spike of run $B$ had an additional enrichment of 9 parts in $10^{4}$ of pure fission produced Ba ${ }^{137}$.

$\mathrm{Ba}^{136} / \mathrm{Ba}^{138} \times 10^{4} \quad \mathrm{Ba}^{135} / \mathrm{Ba}^{138} \times 10^{4} \quad \mathrm{Ba}^{132} / \mathrm{Ba}^{138} \times 10^{4} \quad \mathrm{Ba}^{130} / \mathrm{Ba}^{138} \times 10^{4}$

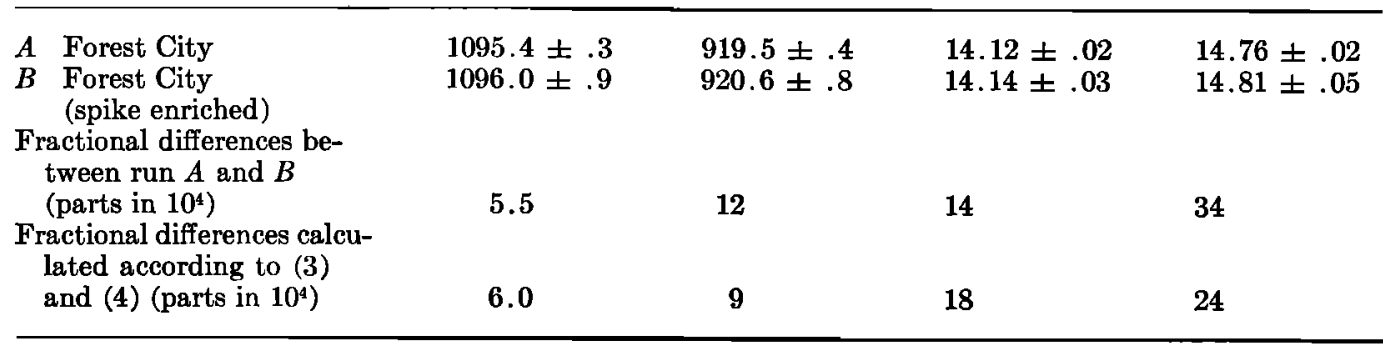


ISOTOPIC ANALYSES OF BARIUM

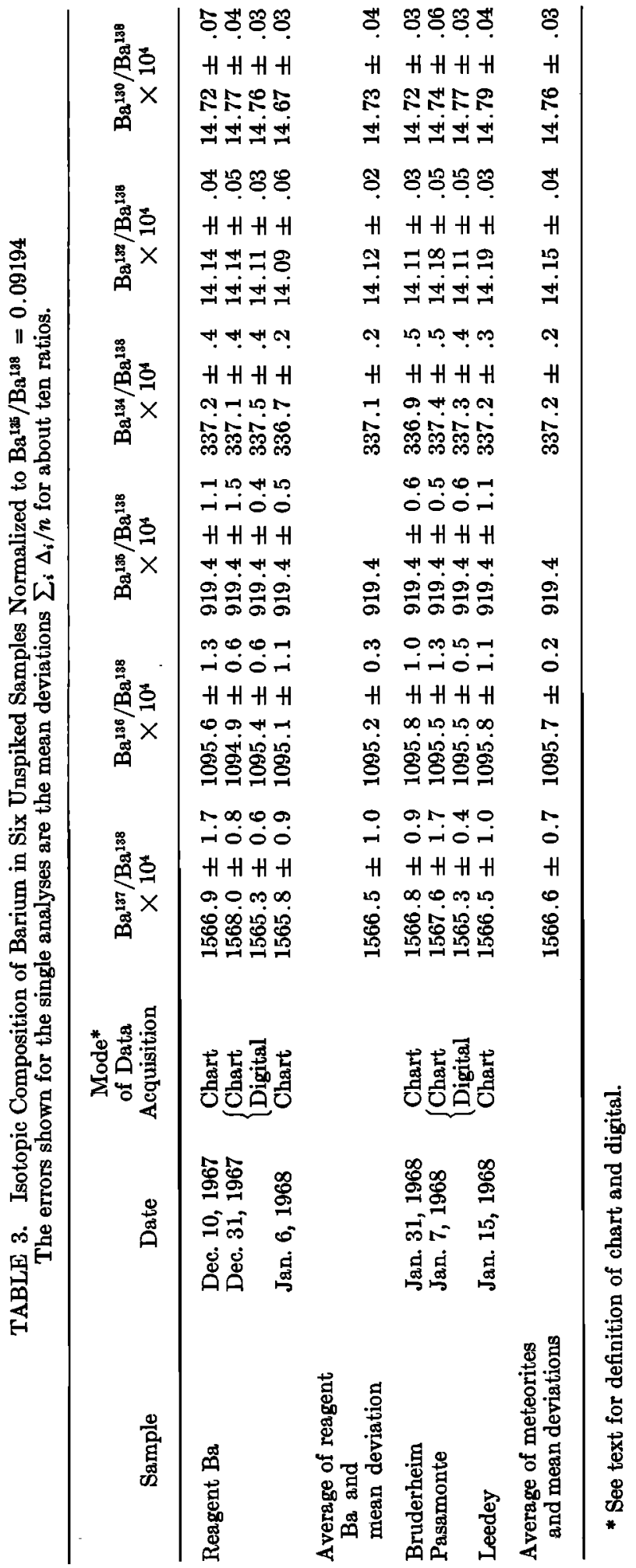


TABLE 4. Isotopic Ratios of Barium in the Investigated Samples after Correction for Fractionation by Means of a Double Spike of $\mathbf{B a}^{134}$ and $\mathrm{Ba}^{137}$

These data are taken with an integrating digital voltmeter.

\begin{tabular}{|c|c|c|c|c|}
\hline & $\mathrm{Ba}^{138} / \mathrm{Ba}^{138} \times 10^{4}$ & $\mathrm{Ba}^{135} / \mathrm{Ba}^{138} \times 10^{4}$ & $\mathrm{Ba}^{132} / \mathrm{Ba}^{199} \times 10^{4}$ & $\mathrm{Ba}^{130} / \mathrm{Ba}^{188} \times 10^{4}$ \\
\hline \multicolumn{5}{|c|}{ Terrestrial Samples } \\
\hline $\begin{array}{l}\text { Reagent } \mathrm{Ba} \\
\text { Terrestrial standard W-1 } \\
\text { Average and mean deviation }\end{array}$ & $\begin{array}{l}1094.5 \pm .8 \\
1095.3 \pm .7 \\
1095.2 \pm .7 \\
1095.0 \pm .3\end{array}$ & $\begin{array}{c}* \\
919.6 \pm .7 \\
919.1 \pm .5 \\
919.4 \pm .3\end{array}$ & $\begin{array}{l}* \\
* \\
*\end{array}$ & $\begin{array}{l}14.76 \pm .1 \\
14.75 \pm .04 \\
14.75 \pm .04 \\
14.75 \pm .003\end{array}$ \\
\hline $\begin{array}{l}\text { Bruderheim a } \\
\text { Leedey b } \\
\text { Forest City } \\
\text { Abee }\end{array}$ & $\begin{array}{l}1095.0 \pm .3 \\
1095.3 \pm .9 \\
1096.7 \pm 1.5 \\
1095.4 \pm .3 \\
1094.5 \pm .8\end{array}$ & $\begin{array}{l}\text { hondrites } \\
\qquad \begin{array}{l}919.3 \pm .3 \\
919.4 \pm .9 \\
919.2 \pm 1.4 \\
919.5 \pm .4 \\
919.1 \pm 1.4\end{array}\end{array}$ & $\begin{array}{c}* \\
* \\
14.12 \pm .02 \\
14.11 \pm .05\end{array}$ & $\begin{array}{l}14.76 \pm .02 \\
14.74 \pm .04 \\
14.74 \pm .05 \\
14.76 \pm .02 \\
14.75 \pm .04\end{array}$ \\
\hline $\begin{array}{l}\text { Pasamonte } \\
\text { Nuevo Laredo }\end{array}$ & $\begin{array}{l}1095.6 \pm 1.0 \\
1095.1 \pm .4\end{array}$ & $\begin{array}{l}\text { chondrites } \\
\qquad 919.5 \pm 1.3 \\
919.4 \pm .6\end{array}$ & $\stackrel{*}{*}{ }^{*} \pm .02$ & $\begin{array}{l}14.74 \pm .05 \\
14.77 \pm .02\end{array}$ \\
\hline $\begin{array}{l}\text { El Taco } \\
\text { Weekeroo Station } \\
\text { Average for all meteorites } \\
\quad \text { and mean deviation }\end{array}$ & $\begin{array}{l}\text { Silicate Inclus } \\
1095.8 \pm .6 \\
1095.6 \pm 1.2 \\
1095.4 \pm .4\end{array}$ & $\begin{array}{l}\text { ions of Iron Meteori } \\
\begin{array}{l}919.7 \pm .6 \\
919.4 \pm 1.0\end{array}\end{array}$ & $\begin{array}{l}14.14 \pm .09 \\
14.13 \pm .02\end{array}$ & $\begin{array}{l}14.77 \pm .09 \\
14.79 \pm .03\end{array}$ \\
\hline
\end{tabular}

* No data taken.

For the individual analyses tabulated, the mean deviations of 10 ratios are shown. The data taken with a strip chart recorder have mean deviations up to four times greater than for the data taken in the digital mode. Furthermore, all values obtained in the analog mode have an additional error of about $0.05 \%$ due to the uncertainty in the correction for the recorder nonlinearity. Because each analysis is normalized to $\mathrm{Ba}^{185} / \mathrm{Ba}^{189}=0.09194$ (the average for nine double spiked samples corrected for fractionation, see Table 4), the scatter for the other ratios is enlarged.

The total spread of the isotopic ratios for all six terrestrial and meteoritic samples in Table 3 is less than $0.2 \%$ for the isotopes $\mathrm{Ba}^{13-188}$ and about $0.8 \%$ for the less abundant isotopes $\mathrm{Ba}^{100}$ and $\mathrm{Ba}^{\mathrm{Ta}}$. The averages for the terrestrial $\mathrm{Ba}$ agree well with those for the meteoritic $\mathrm{Ba}$; the differences are $0.2 \%$ or less and they are well within the experimental errors. Thus, we can conclude, so far, that there are no anomalies caused by nuclear processes in these meteorites at any particular mass position.

Table 4 shows the isotopic ratios of $\mathrm{Ba}$ in three terrestrial and nine meteoritic samples after correction for the mass spectrometer fractionation and of the contribution of $\mathrm{Ba}^{130,}{ }^{139}, 185,138$, and 138 by the double spike using equations 1 and 2. All data in Table 4 are taken with a single-focusing mass spectrometer with a programmable magnetic field and a digital voltmeter for ion beam integration [Wasserburg et al., 1968, 1969].

The errors in Table 4 were evaluated by calculating new ratios

$$
\left(\mathrm{Ba}^{m} / \mathrm{Ba}^{138}\right)_{8 \mathrm{ampl}}^{\mathrm{a}^{\prime}}
$$

using values for the ratios in equations 1 and 2 differing by one mean deviation from their average measured values and in the direction to give the maximum spread in the two calculated ratios

$$
\left(\mathrm{Ba}^{m} / \mathrm{Ba}^{138}\right)_{\text {aample }}^{\alpha^{\prime}}
$$

Figure 2 shows the values of $\delta^{m}{ }_{18 s}$ plotted versus mass numbers $(m)$ obtained for the data given in Table 4.

Here $\delta^{m}{ }_{18 s}$ is defined by

$$
\delta_{188}^{m}=\frac{\left[\mathrm{Ba}^{m} / \mathrm{Ba}^{138}\right]_{\text {met toorite }}-\left[\mathrm{Ba}^{m} / \mathrm{Ba}^{138}\right]_{\text {average for terr. samplos }}}{\left[\mathrm{Ba}^{m} / \mathrm{Ba}^{138}\right]_{\text {averago sor torr. asmplos }}} \times 10^{3}
$$


$\delta^{\boldsymbol{m}}{ }_{138}$ is the fractional difference in parts per thousand of the isotopic abundance relative to a terrestrial standard.

The total spread of the corrected isotopic ratios for all isotopes of the twelve terrestrial and meteoritic samples is in most cases less than $0.2 \%$. The averages for the meteorites agree with those for the three terrestrial samples within much less than $0.1 \%$ for all isotopes and the agreement between the spiked and the normalized unspiked samples as well within the small experimental errors. By using the lower extreme of the terrestrial average and the upper extreme of the meteoritic average for the ratio $\mathrm{Ba}^{130} / \mathrm{Ba}^{138}$, an upper limit for the fractionation of the meteorites versus the terrestrial samples can be estimated as being less than 2 parts in $10^{4}$ per mass unit.

It is evident that these data show the previous results of Umemoto [1962] to be spurious. The effects he reported are most probably the result of instrumental fractionation, which appears to be characteristic of the so-called La Jolla anom- alies [Murthy, 1960, 1962, 1963; Umemoto, 1962; Shima and Honda, 1963].

We would clearly see an effect of $0.2 \%$ in the average $\mathrm{Ba}^{130}$ or $\mathrm{Ba}^{132}$ abundance. For chondrites this corresponds to a measurable difference of $3 \times 10^{10}$ atoms per gram. This is equivalent to the number of excess atoms of $\mathrm{Xe}^{120}$ which is typically found [Reynolds, 1960b] and attributed to $\mathrm{I}^{120}$ decay.

Our data exclude the production of $\mathrm{Ba}^{\text {190 }}$ and $\mathrm{Ba}^{182}$ by a radioactive precursor with an abundance comparable to that of $\mathrm{I}^{129}$, which enriched the meteoritic $\mathrm{Ba}$ relative to the terrestrial $\mathrm{Ba}$. Furthermore, upper limits can be placed on differences in integrated high-energy proton fluxes for uniform irradiation conditions in the early history of the solar system. If an average target concentration of $5 \mathrm{ppm}$ at about mass 140 and an effective spallation cross section of $10 \mathrm{mb}$ are assumed, a high-energy proton flux of about $5 \times 10^{19}$ protons $/ \mathrm{cm}^{2}$ is required to enrich $\mathrm{Ba}^{130}$ or $\mathrm{Ba}^{120}$ in chondrites by $0.2 \%$. This is one order of magnitude higher than the upper

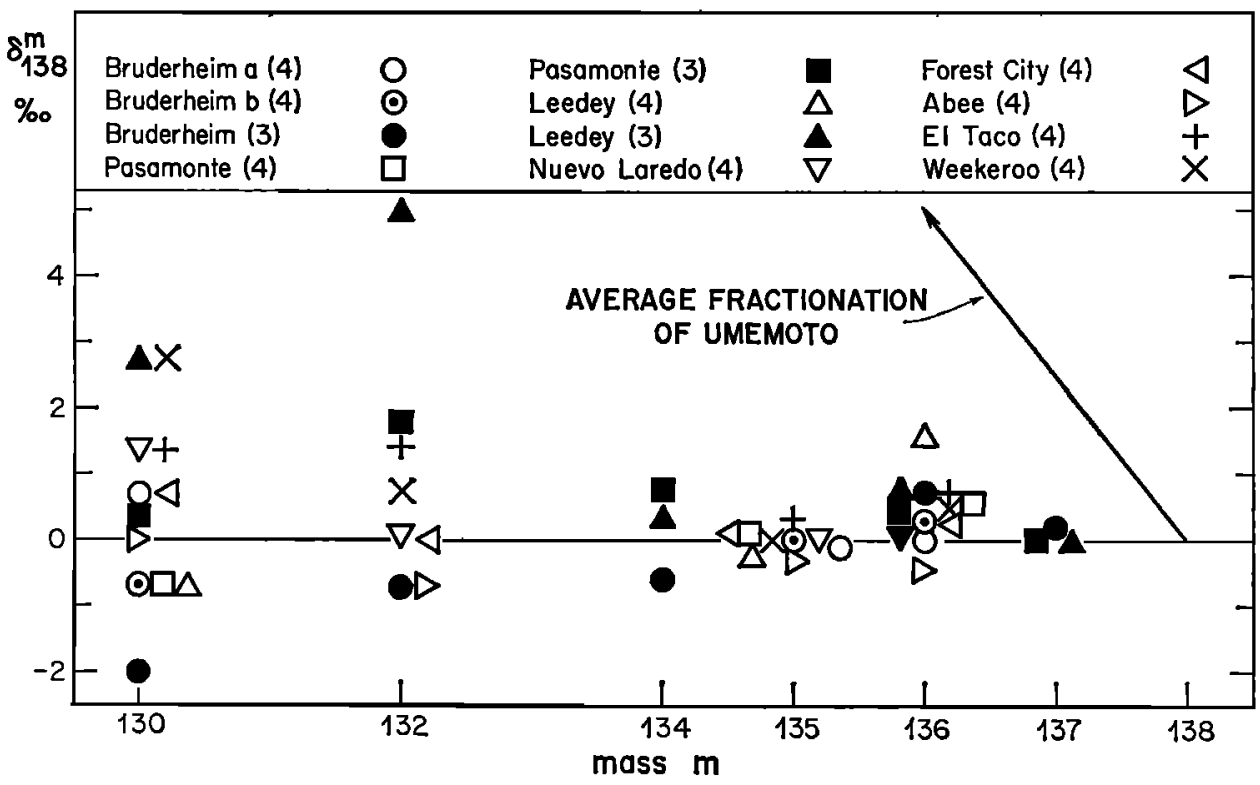

Fig. 2. Barium $\delta^{m}{ }_{189}$ values for the investigated meteorites. The numbers (3) and (4) after the meteorite names refer to the corresponding table in this work.

$$
\delta^{m}{ }_{188}=\frac{\left[\mathrm{Ba}^{m} / \mathrm{Ba}^{138}\right]_{\text {meteorlte }}-\left[\mathrm{Ba}^{m} / \mathrm{Ba}^{188}\right]_{\text {average for terr. samplea }}}{\left[\mathrm{Ba}^{m} / \mathrm{Ba}^{188}\right]_{\text {avoreso for terr. mawdes }}} \times 10^{2}
$$

The fractionation line to be expected from the work of Umemoto [1962] is shown for comparison. 
TABLE 5. Concentration of Barium in the Investigated Samples

Metallic iron was magnetically removed from the Leedey and Abee samples, but not from all other samples.

\begin{tabular}{|c|c|c|c|}
\hline \multirow[b]{2}{*}{ Sample } & \multirow[b]{2}{*}{ Class } & \multicolumn{2}{|c|}{ Ba Concentration, ppm } \\
\hline & & This Work & Literature Values \\
\hline $\begin{array}{l}\text { Bruderheim } \\
\text { Leedey } \\
\text { Forest City } \\
\text { Abee } \\
\text { Pasamonte } \\
\text { Nuevo Laredo } \\
\text { El Taco } \\
\text { Weekeroo Station } \\
\text { Terrestrial standard W-1 }\end{array}$ & $\begin{array}{l}\text { L chondrite } \\
\text { L chondrite } \\
\text { H chondrite } \\
\text { Enstatite chondrite } \\
\text { Eucrite } \\
\text { Eucrite } \\
\text { Ni-poor ataxite } \\
\text { Octahedrite }\end{array}$ & $\begin{array}{c}3.37 \\
3.85 \\
3.37 \\
2.41 \\
28.2 \\
39.3 \\
2.37 \\
8.70 \\
158\end{array}$ & $\begin{array}{l}3.4^{f} \\
3.76^{a} \\
3.65^{a}, 4.1^{d}, 9^{c} \\
2.41^{a} \\
28.6^{a}, 26^{c} \\
39.4^{a}, 40^{c}, 46^{d}\end{array}$ \\
\hline
\end{tabular}

- Tera, Burnett, and Wasserburg, to be published.

${ }^{b}$ Schnetzler et al. [1967].

- Duke and Silver [1967].

¿ Hamaguchi et al. [1957].

- Pinson et al. [1953].

$f$ Wyttenbach and Dulakas (private communication, 1965).

limit of $3 \times 10^{18}$ particles $/ \mathrm{cm}^{2}$ for $>500-\mathrm{Mev}$ particles calculated by Burnett et al. [1966] based on isotopic analyses of potassium in terrestrial and meteoritic samples. The latter experiment is of course much more sensitive for the determination of an upper limit for the flux of an early irradiation of the solar system.

Barium concentrations. The concentration of $\mathrm{Ba}$ found in the meteorites and in the diabase standard $\mathrm{W}-1$ is given in Table 5. A small laboratory blank contribution of less than $2 \%$ was corrected. The analytical error in these figures is less than $1 \%$. The differences between these values and the results obtained by other authors are most probably due to inhomogeneities of the meteorites.

Isotopic composition of natural barium. The values in Table 6 given for this work represent the averages for both meteorites and terrestrial samples, since no differences in the isotopic composition have been found. The ratios $\mathrm{Ba}^{137} / \mathrm{Ba}^{139}$ and $\mathrm{Ba}^{134} / \mathrm{Ba}^{139}$ represent the averages of the six unspiked samples (Table 3), whereas the other ratios represent the averages for the data tabu-

TABLE 6. Isotopic Composition of Barium

The errors of this work equal $3 \sigma_{\text {mean }}=3\left[\sum \Delta x_{i}{ }^{2} / n(n-1)\right]^{1 / 2}$ calculated from the mean values for each mass spectrometer analysis as given in Tables 3 and 4 . Nier believes his ratios to be correct within $2 \%$ except the ones for $\mathrm{Ba}^{130}$ and $\mathrm{Ba}^{132}$, which may be in error by $4 \%$. The errors given by us for the values of Umemoto have been recalculated by us from his data to correspond to $3 \sigma_{\text {mean }}$ for six analyses.

\begin{tabular}{|c|c|c|c|c|c|c|}
\hline & $\begin{array}{c}\mathrm{Ba}^{137} / \mathrm{Ba}^{138} \\
\times 10^{4}\end{array}$ & $\begin{array}{c}\mathbf{B a}^{136} / \mathrm{Ba}^{138} \\
\times 10^{4}\end{array}$ & $\begin{array}{c}\mathrm{Ba}^{{ }^{135}} / \mathrm{Ba}^{138} \\
\times 10^{4}\end{array}$ & $\begin{array}{c}\mathbf{B a}^{134} / \mathbf{B a}^{138} \\
\times 10^{4}\end{array}$ & $\begin{array}{c}\mathrm{Ba}^{122} / \mathrm{Ba}^{138} \\
\times 10^{4}\end{array}$ & $\begin{array}{c}\mathrm{Ba}^{130} / \mathrm{Ba}^{138} \\
\times 10^{4}\end{array}$ \\
\hline $\begin{array}{l}\text { This work } \\
\text { Nier [1938] } \\
\text { Umemoto [1962] } \\
\text { Values of } \\
\text { Umemoto } \\
\text { normalized to } \\
\mathrm{Ba}^{136} / \mathrm{Ba}^{138}= \\
0.09194\end{array}$ & $\begin{array}{l}1566.5 \pm 0.5 \\
1580 \\
1547.9 \pm 3.0\end{array}$ & $\begin{array}{l}1095.3 \pm 0.5 \\
1090 \\
1086.8 \pm 2.7\end{array}$ & $\begin{array}{l}919.4 \pm 0.2 \\
920 \\
908.0 \pm 2.4\end{array}$ & $\begin{array}{l}337.1 \pm 0.3 \\
337 \\
331.97 \pm 1.0\end{array}$ & $\begin{array}{l}14.12 \pm 0.02 \\
13.6 \\
13.712 \pm 0.05\end{array}$ & $\begin{array}{l}14.76 \pm 0.02 \\
14.1 \\
14.215 \pm 0.06\end{array}$ \\
\hline
\end{tabular}


TABLE 7. Percentage Abundances of the Isotopes of Barium

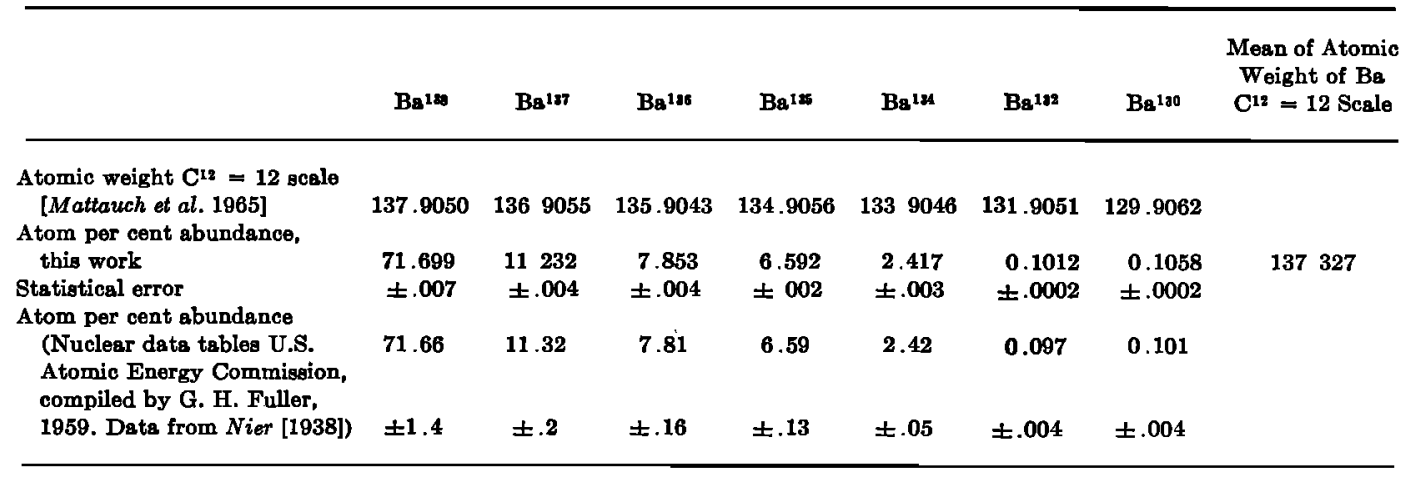

lated in Table 4. The error for the ratios $\mathrm{Ba}^{130,}{ }^{132,}{ }^{133,}{ }^{189} / \mathrm{Ba}^{139}$ introduced by the correction of the contribution of the double spike is less than $0.1 \%$.

The given errors do not include the uncertainty of the gravimetrically determined value of $\mathrm{Ba}^{13 \pi} / \mathrm{Ba}^{134}$ on which the correction of the laboratory fractionation is based. These data represent our best estimates of the absolute ratios, although it should be clear that the purpose of this work was to search for isotopic variations and not to establish absolute ratios, which require better gravimetric procedures than used here. The data in Table 6 are all self-consistent to within the precision given with a fixed fractionation per mass unit.

In Table 6 the isotopic composition obtained in this work is compared with the terrestrial composition given by Nier [1938] and by Umemoto [1962]. If we normalize Umemoto's values to $\mathrm{Ba}^{135} / \mathrm{Ba}^{189}=0.09194$ and extend the errors that he reports to a $99 \%$ confidence limit, his results are compatible with the data reported here.

The abundances given by Nier [1938] are, as usual, confirmed to be correct within the error limits that he quotes. The results presented here should supersede these data as they are more precise and significantly revise the abundances of the light isotopes $\mathrm{Ba}^{130}$ and $\mathrm{Ba}^{122}$ for which we obtain about $4 \%$ higher abundances. The percentage abundances which correspond to the abundance ratios found in our work are given in Table 7 . With isotopic weights according to the $\mathrm{C}^{\text {ta }}=12$ scale [Mattauch et al., 1965] one calculates an atomic weight of 137.327 for Ba.
Acknowledgments. We wish to thank D. S. Burnett for valuable discussions and suggestions and D. A. Papanastassiou for his support in the mass spectrometry. We are indebted to our colleagues who supplied meteorite samples used in this work: Pasamonte, Leedey, Forest City, and Weekeroo Station were obtained from the Nininger Meteorite Collection at the Arizona State University through the aid of C. W. Moore. El Taco was obtained from H. Hintenberger, M.P.I., Mainz, Germany. Bruderheim was given to us by L. T. Silver from a sample provided to him by R. E. Folinsbee. Nuevo Laredo was given to us by L. T. Silver. Abee was provided by J. A. V. Douglas, Geological Survey of Canada.

This work was supported by the National Science Foundation (grants GP 9114 and GP 7976).

\section{References}

Burnett, D. S., H. J. Lippolt, and G. J. Wasserburg, The relative isotopic abundance of $K^{40}$ in terrestrial and meteoritic samples, J. Georhys. Res., 71, 1249, 1966. (See also; Correction, J. Geophys. Res., $71,3609,1966$.

Chakraburtty, A. K., C. M. Stevens, H. C. Rushing, and E. Anders, Isotopic composition of silver in iron meteorites, J. Geophys. Res., 69, 505, 1964.

Crouch, E. A., and T. A. Tuplin, Isotopic composition and the atomic weight of naturally occurring molybdenum: A possible reflexion of the creation process, Nature, 202, 1282, 1964.

Duke, M. B., and I. T. Silver, Petrology of eucrites, howardites, and mesosiderites, Geochim. Cosmochim. Acta, 31, 1637, 1967.

Eugster, O., P. Eberhardt, and J. Geiss, The isotopic composition of krypton in unequilibrated and gas rich chondrites, Earth Planetary Sci. Letters, $2,385,1967$.

Gradsztajn, E., M. Salome, A. Yaniv, and R. Bernas, Isotopic analysis of lithium in the Holbrook meteorite and in terrestrial samples with a sputtering ion source mass spectrometer, Earth Planetary Sci. Letters, 3, 387, 1967. 
Hamaguchi, H., G. W. Reed, and A. Turkevich, Uranium and barium in stone meteorites, Geochim. Cosmochim. Acta, 12, 337, 1957.

Krummenacher, D., C. M. Merrihue, R. O. Pepin, and J. H. Reynolds, Meteoritic krypton and barium versus the general isotopic anomalies in meteoritic xenon, Geochim. Cosmochim. Acla, 26, 231, 1962.

Mattauch, J. H. E., W. Thiele, and A. H. Wapstra, 1964 atomic mass table, Nucl. Phys., 67, 1, 1965.

Murthy, V. R., Isotopic composition of silver in an iron meteorite, Phys. Rev. Letters, 5, 539, 1960.

Murthy, V. R., Isotopic anomalies of molybdenum in some iron meteorites, $J$. Geophys. Res., 67, 905, 1962.

Murthy, V. R., Elemental and isotopic abundances of molybdenum in some meteorites, Geochim. Cosmochim. Acta, 27, 1171, 1963.

Murthy, V. R., Stable isotope studies of some heavy elements in meteorites, in Isotopic and Cosmic Chemistry, edited by $\mathbf{H}$. Craig, S. L. Miller, and G. J. Wasserburg, 488 pp. North Holland, Amsterdam, 1964.

Nier, A. O., The isotopic constitution of strontium, barium, bismuth, thallium, and mercury, Phys. Rev., 54, 275, 1938.

Pepin, R. O., Trapped neon in meteorites, Earth Planetary Sci. Letters, 2, 13, 1967.

Pinson, W. H., L. H. Ahrens, and M. L. Franck, The abundances of $\mathrm{Li}, \mathrm{Sc}, \mathrm{Sr}, \mathrm{Ba}$, and $\mathrm{Zr}$ in chondrites and some ultramafic rocks, Geochim. Cosmochim. Acta, 4, 251, 1953.

Reynolds, J. H., Determination of the age of the elements, Phys. Rev. Letters, 4, 8, $1960 a$.

Reynolds, J. H., Isotopic composition of primordial xenon, Phys. Rev. Letters, 4, 351, 1960 b.

Schnetzler, C. C., H. H. Thomas, and J. A. Philpotts, The determination of barium in G-1 and W-1 by isotope dilution, Geochim. Cosmochim. Acta, 31, 95, 1967.

Shields, W. R., ed., NBS Tech. Note $27 \%, 1966$.

Shima, M., and M. Honda, Isotopic abundance of meteoritic lithium, J. Geophys. Res., 68, 2849, 1963.

Umemoto, S., Isotopic composition of barium and cerium in stone meteorites, J. Geophys. Research, 67, 375, 1962.

Wasserburg, G. J., D. A. Papanastassiou, E. V. Nenow, and C. A. Bauman, A programmable magnetic field mass spectrometer with on-line data processing (abstract), Trans. Am. Geophys. Union, 49, 350, 1968.

Wasserburg, G. J., D. A. Papanastassiou, E. V. Nenow, and C. A. Bauman, A programmable magnetic field mass spectrometer with on-line data processing, Rev. Sci. Instr., 40(2), 288, 1969.

Wetherill, G. W., Isotopic composition and concentration of molybdenum in iron meteorites, J. Geophys. Res., 69, 4403, 1964.

\section{(Received January 24, 1969;} revised April 1, 1969.) 